\title{
An Elusive Persistent Left Superior Vena cava Draining into Left Atrium
}

\author{
Alan Soward, Folkert ten Cate, Paolo Fioretti, Jos Roelandt, Patrick W. Serruys ${ }^{1}$ \\ Heart Catheterization Laboratory, Thoraxcenter, Erasmus University, Rotterdam, The Netherlands
}

Key Words. Left superior vena cava · Left atrium · Cardiac catheterization · Contrast echocardiography

\begin{abstract}
A case report of a persistent left superior vena cava draining into left atrium with a fibromuscular left ventricular outflow tract obstruction and a small atrial septal defect. The anomalous vessel escaped detection during two right and left heart catheterizations from the right arm and open heart surgery. It was an incidental finding during cardiac catheterization from the left arm and the anatomy was confirmed by contrast echocardiography.
\end{abstract}

\section{Introduction}

A persistent left superior vena cava (LSVC) occurs in 3-4\% of patients with congenital heart disease [1, 2]. This usually coexists with other cardiac abnormalities and drains into the right atrium (RA) via the coronary sinus. Exceptionally, the LSVC drains into the left atrium (LA) either indirectly via an unroofed coronary sinus [3] or directly. This case report is of a LSVC draining directly into the $\mathrm{LA}$, associated with an atrial septal defect and a fibromuscular left ventricular outflow tract obstruction. It highlights the difficulty in diagnosing the presence of such an unsuspected anomalous vessel.

1 With the technical assistance of Jackie McGhie.

\section{Case Report}

The patient presented in 1971 aged 32 years with a long history of worsening exertional dyspnea. She looked well and had no cyanosis or clubbing. Peripheral pulses and blood pressure impulse were normal. A loud pansystolic murmur was heard at the apex and a systolic ejection murmur at the third left interspace. The ECG showed sinus rhythm and left ventricular hypertrophy and the chest X-ray was suggestive of left ventricular hypertrophy. Right and left heart catheterization was performed from the right arm. The left ventricular outflow tract was narrowed by a dynamic rim of trabecularized tissue and moderate mitral regurgitation was present. The hemoglobin level was within the normal range and oxygen saturations were also normal (table I). At surgery. cannulae were inserted into normal superior and inferior vena cavae and cardiopulmonary bypass was apparently instituted without difficulty. The left ventricle was hyperthrophied and the outflow tract narrowed by fibrous tissue extending over much of the septum. This was 
A
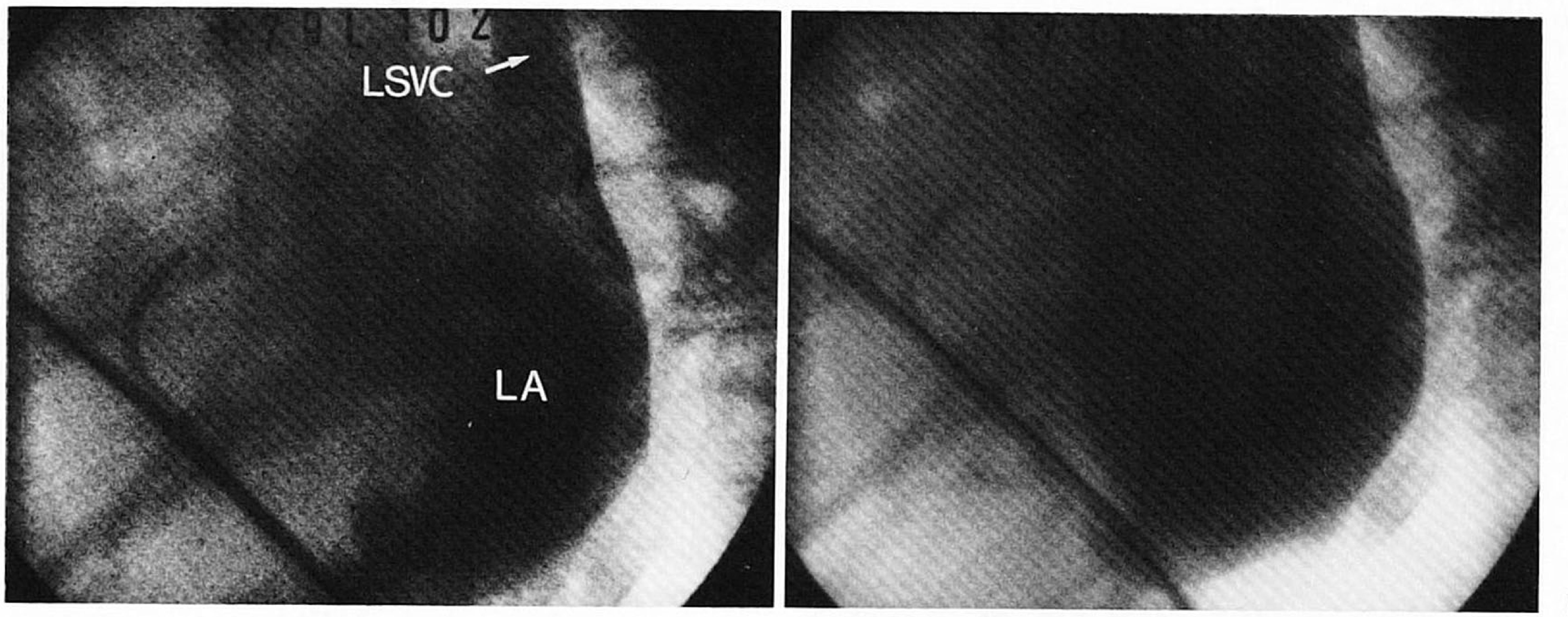

Fig. 1. Contrast injection into the left superior vena cava (LSVC) from above. Contrast can be seen entering (A) and opacifying (B) the left atrium (LA). Left anterior oblique view.

resected via an aortic approach. The mitral valve appeared satisfactory when inspected across the aortic valve and was not replaced. A left atriotomy was not performed and venous blood was not seen entering the surgical field through the mitral valve.

Although improved, some symptoms persisted and in 1975, repeat cardiac catheterization from the right arm found the resting left ventricular outflow tract gradient to be improved and moderate mitral regurgitation was again present. Various medications were tried with limited success and in 1979 another cardiac catheterization was performed. Technical difficulties were encountered and the procedure was performed from the left cubital fossa. The venous catheter passed without obstruction along a LSVC into the LA. The anatomy was confirmed by angiography with contrast injections into the LSVC (fig. 1) and a retrogradely cannulated pulmonary vein. A small amount of contrast entered the RA via a low atrial septal defect during angiography. The LSVC entered the upper left corner of the LA and although no communication was seen between the LSVC and the presumably normal right superior vena cava (RSVC), such a channel was not definitely excluded. There was no oximetric evidence of significant left to right shunting (table I). Other catheterization findings were similar to those of 1975 and further operative intervention was decided against.

Contrast echocardiography using Haemaccel injected into a left antecubital vein was undertaken in
Table I. Oxygen saturations (\%) obtained during catheterization in 1971 and 1979

\begin{tabular}{lll}
\hline & 1971 & 1979 \\
\hline RSVC & 79 & 77 \\
LSVC & - & 85 \\
RA & 77 & 78 \\
RV & 78 & 77 \\
PA & 80 & 77 \\
LA & - & 95 \\
LV & 95 & 94 \\
\hline
\end{tabular}

RSVC = Right superior vena cava; LSVC = left superior vena cava; $\mathrm{RA}=$ right atrium; $\mathrm{RV}=$ right ventricle; $\mathrm{PA}=$ pulmonary artery; $\mathrm{LA}=$ left atrium; $L V=$ left ventricle.

1984. With each injection, on both the M-mode and the cross-sectional echocardiograms, the LA was directly opacified with dense echoes, these echoes being of greater density when the injection was given immediately before the release phase of a Valsalva maneuver (fig. 2), a procedure performed to increase the venous return to the heart. Subsequently, fainter echoes appeared within the RA appearing on crosssectional echocardiography to pass directly from the LA to the RA via the atrial septal defect. 


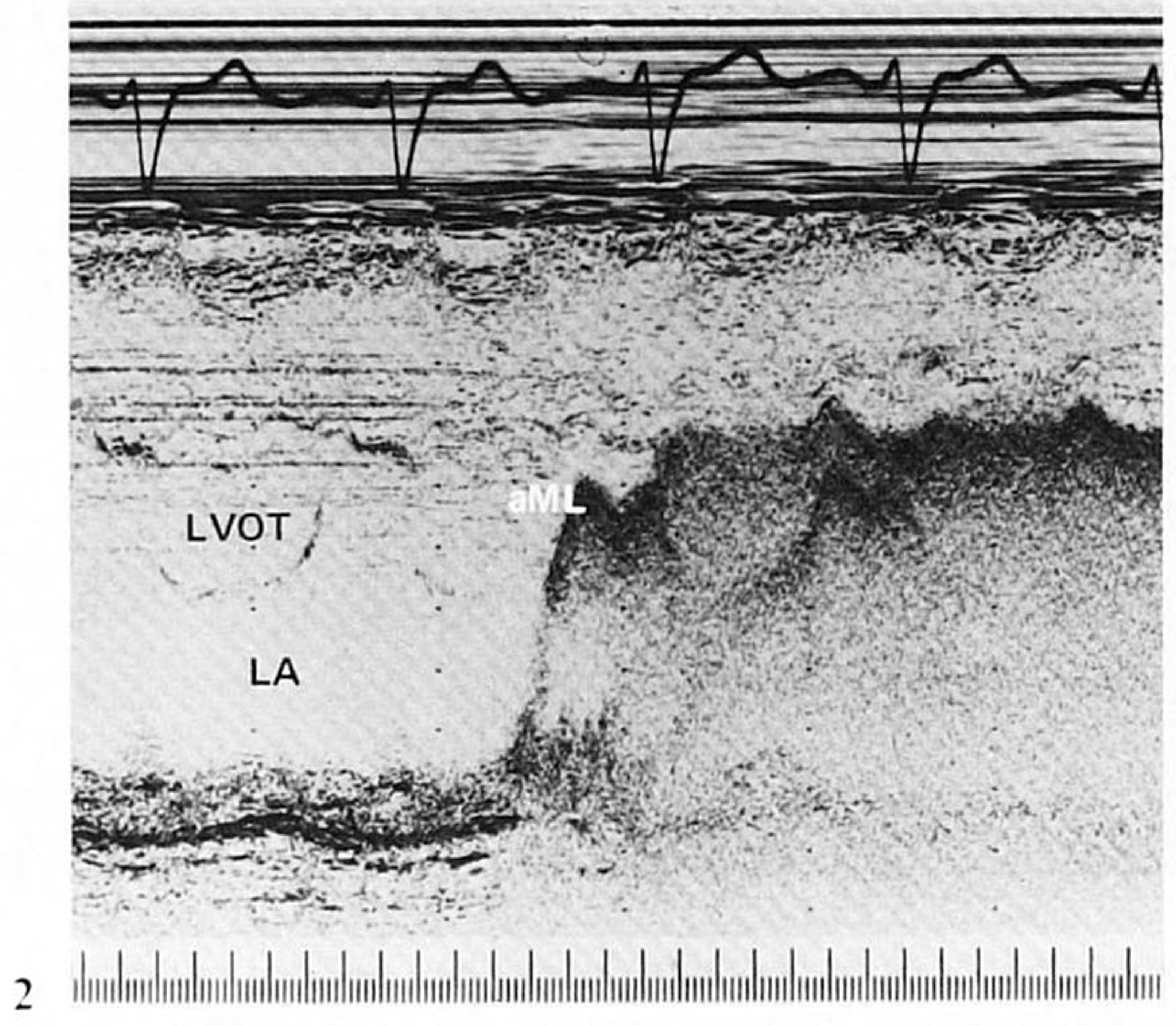

Fig. 2. M-mode echocardiogram showing contrast injected into a left antecubital vein appearing directly in the left atrium (LA) and then in the left ventricular

\section{Comments}

A persistent LSVC draining through the coronary sinus into the RA is not infrequent finding during cardiac catheterization or heart surgery, but probably has no functional importance. A large coronary sinus may be a clue as to the presence of this anomaly. Defects in the roof of the coronary sinus may allow communication with the LA [4].

Very rarely, the LSVC may drain entirely into the LA. The resultant venous drainage from the upper body has three variations [5] (fig. 3): (A) the LSVC may communicate with a normal RSVC via the left innominate vein; (B) with agenesis of the left innominate vein, the vena cavae drain separately into their respective atria; (C) the RSVC may be absent with all the blood from the upper body returning via the LSVC, constituting a considerable right to left shunt. Cases of an otherwise normal RSVC draining into the LA

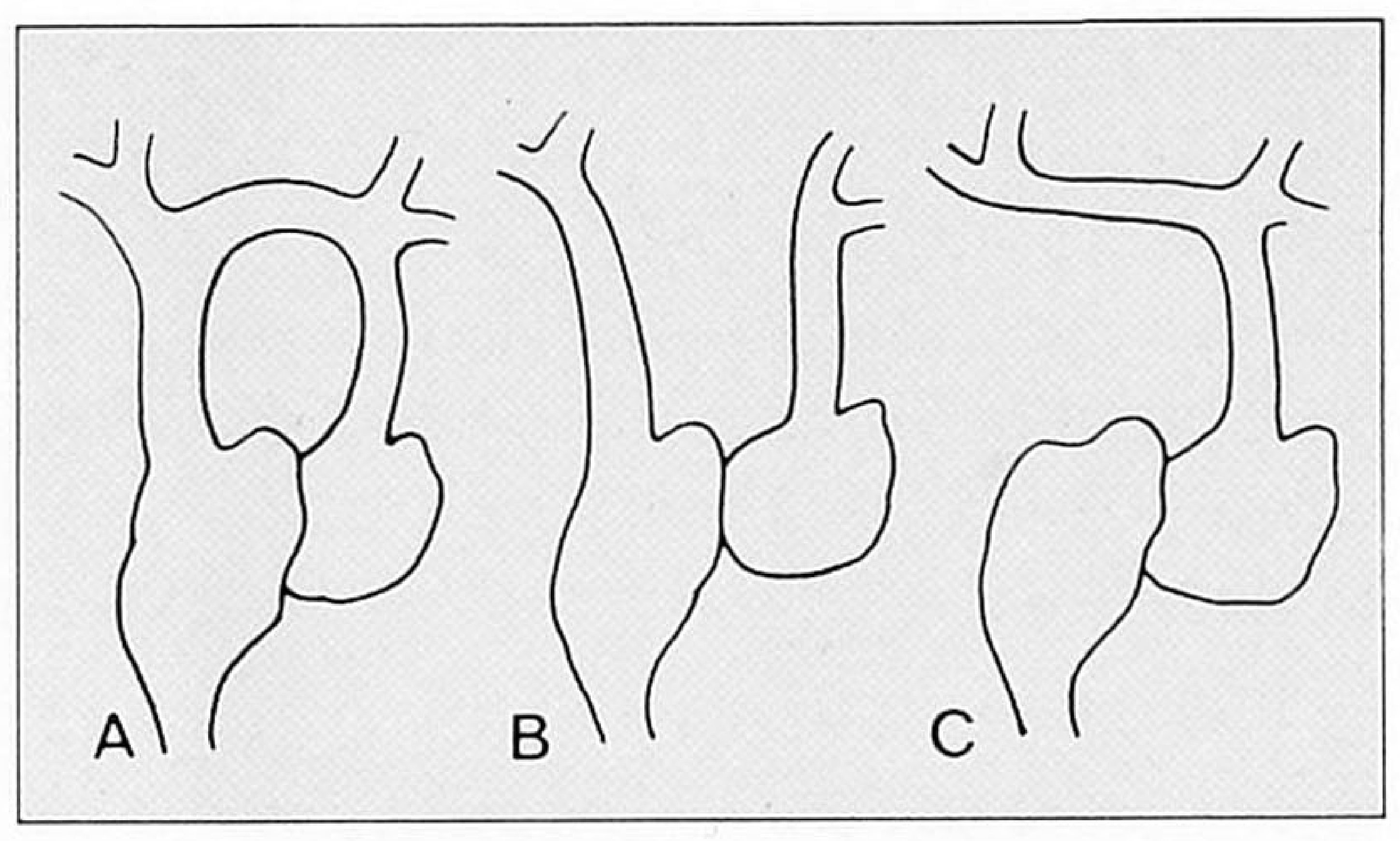

outflow tract $($ LVOT) aML = Anterior mitral valve leaflet. Contrast was injected immediately before the release phase of the Valsalva maneuver.

Fig. 3. Illustration of the drainage of an anomalous left superior vena cava into the left atrium. A With communication of the two cavae via the left innominate. B With agenesis of the left innominate vein. $\mathrm{C}$ With agenesis of the right superior vena cava. From Shumacker et al. [5], with permission.

have been reported [6] and contrast echocardiography has been used in the diagnosis of a persistent LSVC draining into a coronary sinus with LA communications [7] and in the diagnosis of an anomalous connection of the RSVC to the LA [8]. Bidirectional shunting was demonstrated in our patient, but to a small degree. The L-R shunting was clearly shown at the low atrial level by angiography and echocardiography. A patent left innominate joining the two vena cavae has not been excluded but would seem unlikely as there was no late filling of the RA during left atrial angiography nor was there appearance of echo-dense microbubbles in the right atrium from a superior direction during echocardiography. The presence of such a channel has been used to explain the absence of a significant degree of R-L shunting [9]. Contrast echocardiography provided confirmatory evidence of the direct drainage of the LSVC into the LA and indicated the potential route 
for systemic emboli. Cerebral abscesses and emboli have been described in association with the shunting $[3,4]$. In view of the relative rarity of upper limb venous thrombosis, prophylactic anticoagulation would seem unwarranted and we have advised our patient to seek prompt treatment of established infections. Because of the mitral valve disease, antibiotic prophylaxis prior to minor surgical interventions is indicated but would not be indicated for the LSVC or the atrial septal defect alone.

A persistent LSVC draining directly into the LA is a very rare but clinically significant condition and its association with a fibromuscular left ventricular outflow tract obstruction is previously unreported. It was an unexpected finding and its presence was easily confirmed by echocardiography with contrast injection into a left antecubital vein. This latter technique should be considered to exclude anomalous drainage of a persistent LSVC into LA in patients with congenital heart disease or those in whom an unexplained R-L shunt is present.

\section{References}

1 Campbell, M.; Deuchar, D.C.: The left sided superior vena cava. Br. Heart J. 16: 423-439 (1954).

2 Fraser, R.S.; Dvorkin, J.; Rossall, R.E.; Eidem, R.: Left superior vena cava. A review of associated congenital heart lesions, catheterization data and roentgenologic findings. Am. J. Med. 31: 711-716 (1961).
3 Raghib, G.: Ruttenberg, H.D.: Anderson, R.C.; Amplatz. K.: Adams, P., Jr.: Edwards. J.E.: Termination of left superior vena cava in left atrium. atrial septal defect, and absence of coronary sinus. Circulation 31: 906-918 (1965).

4 Quaegebeur, J.; Kirklin, J.W.; Pacifico, A.D.; Bargeron, L.M., Jr.: Surgical experience with unroofed coronary sinus. Ann. thor. Surg. 27: 418-425 (1979).

5 Shumacker, H.B.; King, H.; Waldhausen, J.A.: The persistent left superior vena cava. Surgical implications, with special reference to caval drainage into the left atrium. Ann. Surg. 165: 797-805 (1967).

6 Park, H.M.; Summerer, M.H.; Preuss, K.; Armstrong, W.F.; Mahomed, Y.; Hamilton, D.J.: Anomalous drainage of the right superior vena cava into the left atrium. J. Am. Coll. Cardiol. 2: 358-362 (1983).

7 Bourdillon, P.D.; Foale, R.A.; Somerville, J.: Persistent left superior vena cava with coronary sinus and left atrial communications. Eur. J. Cardiol. 11: 227-234 (1980).

8 Truman, A.T.; Rao, P.S.; Kulangara, R.J.: Use of contrast echocardiography in diagnosis of anomalous connection of right superior vena cava to left atrium. Br. Heart J. 44: 718-723 (1980).

9 Meadows, W.R.; Sharp, J.T.: Persistent left superior vena cava draining into the left atrium without arterial oxygen unsaturation. Am. J. Cardiol. 16: 273-279 (1965).

Received: June 14, 1985

Accepted after revision: December 29, 1985

Patrick W. Serruys, MD,

Catheterization Laboratory,

Thoraxcenter,

Erasmus University,

Dr. Molenwaterplein 40,

NL-3015 GD Rotterdam (The Netherlands) 